OLIVEIRA, Inês Cavadas de; ANDRADE, Helena Rebelo de; MIGUEL, José Pereira. O Museu da Saúde em Portugal: um espaço físico, um espaço virtual. História, Ciências, Saúde - Manguinhos, Rio de Janeiro, v.22, supl., dez. 2015, p.17491763.

\title{
O Museu da Saúde em Portugal: um espaço físico, um espaço virtual
}

\section{The Museu da Saúde in Portugal: a physical space, a virtual space}

Inês Cavadas de Oliveira

Museóloga, Museu da Saúde (MS)/ Instituto Nacional de Saúde Doutor Ricardo Jorge (Insa).

\section{Helena Rebelo de Andrade \\ Coordenadora, MS/Insa.}

\section{José Pereira Miguel}

Presidente, Insa.

Insa.

Avenida Padre Cruz, s.n.

1649-016 - Lisboa - Portugal

museudasaude@insa.min-saude.pt

Resumo

O Museu da Saúde em Portugal, baseado no duplo conceito de espaço físico polinucleado e espaço virtual, desenvolve o inventário do seu acervo, tendo, até ao momento, estudado mais aprofundadamente cinco das suas coleções - Tuberculose, Urologia, Psicologia, Medicamento e Malária. Neste artigo, o museu apresenta essas coleções, bem como a problemática do desenvolvimento da atividade museológica no espaço de um laboratório nacional, o Instituto Nacional de Saúde Doutor Ricardo Jorge, salientando as questões dos espaços de reserva e de exposição, o processo de inventário e as atividades de divulgação, atendendo aos desafios inerentes a uma atividade desenvolvida num espaço não museológico.

Palavras-chave: ação educativa; coleção; inventário museológico; divulgação; Portugal.

\section{Abstract}

Museu da Saúde (Museum of Health) in Portugal, based on the dual concept of a multifaceted physical space and a virtual space, is preparing an inventory of its archive. So far, it has studied five of its collections in greater depth: tuberculosis, urology, psychology, medicine, and malaria. In this article, these collections are presented, and the specificities of developing museological activities within a national laboratory, Instituto Nacional de Saúde Doutor Ricardo Jorge, are also discussed, highlighting the issues of the store rooms and exhibition spaces, the inventory process, and the communication activities, with a view to overcoming the challenges inherent to operating in a non-museological space.

Keywords: educational action; collection; museological inventory; communication; Portugal. 
$\mathrm{N}$ a sua génese, o Museu da Saúde em Portugal apresenta um duplo conceito - um espaço físico polinucleado ${ }^{1}$ para apresentação das coleções; um espaço virtual ${ }^{2}$ de divulgação do acervo e das atividades educativas e culturais, dirigidas ao público escolar, a investigadores e profissionais da área da saúde. Considerando que, em muitos casos, a manutenção dos acervos no local de origem constitui uma valorização do património e uma premissa fundamental para a compreensão dele, o Museu da Saúde não pretende centralizar os objetos num único espaço, mas, antes, promover núcleos de cariz museológico com os quais estabeleça sinergias para a preservação e divulgação dos objetos à comunidade. Porém, pretende-se que a informação e o conhecimento gerados no decorrer do processo de inventário e documentação das coleções sejam acessíveis e, nesse caso, centralizados. Para isso, e com claras vantagens para a investigação na área da saúde, o museu desenvolveu um portal em que disponibiliza o inventário on-line do seu acervo, bem como das instituições parceiras, permitindo ao público em geral e aos investigadores obter informação sobre as diferentes coleções das várias instituições com as quais o Museu da Saúde estabeleceu parcerias. ${ }^{3}$

\section{Conceito}

O avanço das tecnologias da saúde e a reestruturação de serviços foram dois dos fatores que levaram, num espaço de tempo relativamente curto, a que instrumentos, aparelhos e documentos se tornassem obsoletos para as práticas médicas contemporâneas, obrigando à sua substituição.

Deixando de ter uma utilidade prática no dia a dia das instituições, esses objetos e documentos ganharam um novo estatuto - o de testemunhos de práticas, técnicas e saberes. Conscientes disso, alguns serviços de saúde desenvolveram a tentativa de preservação do equipamento desatualizado, considerado de interesse histórico por critérios subjetivos e aleatórios, armazenando-o em condições de conservação variáveis, geralmente incorretas e sem segurança, disperso pelos diversos serviços dependentes do Ministério da Saúde em Portugal. À falta de condições adequadas de acondicionamento, acrescenta-se a inexistência de técnicos com formação especializada, situações perfeitamente normais na medida em que um processo de preservação de património ultrapassa o âmbito e os objetivos dos serviços que prestam cuidados de saúde.

Como muitas vezes se afirma, quando nos referimos à dificuldade em preservar os bens da ciência e tecnologia (C\&T), esse património é um "órfão institucional":

Tipicamente gerado em instituições que não dispõem dos mecanismos, políticas, recursos, vocação ou pessoal qualificado para a sua preservação - universidades, hospitais, antigos liceus, sociedades científicas, laboratórios, empresas, associações - e fora do domínio da tutela da cultura, os artefactos vivem na arbitrariedade. Caso existam na instituição pessoas sensíveis à sua importância, estes são preservados, por vezes durante longos períodos, em situações de extrema precariedade (Lourenço, 2012, no prelo).

Consciente dessa realidade, o Ministério da Saúde em Portugal, organismo responsável pela gestão desses espaços, determinou que fosse constituído o Museu da Saúde, como unidade dependente do Instituto Nacional de Saúde Doutor Ricardo Jorge, Instituto Público (Insa, IP),${ }^{4}$ em Lisboa. 
Assim, no contexto de reformulação da estrutura orgânica desse instituto, cometendolhe novas atribuições, o decreto-lei 271/2007 (Portugal, 26 jul. 2007) definiu como uma das missões e atribuições do Insa, IP a difusão da cultura científica e, nesse contexto, mencionou, pela primeira vez, a instalação e gestão do Museu da Saúde em Portugal.

No desenvolvimento desse decreto-lei, foram concebidos os estatutos, que determinaram a nova estrutura do Insa, IP onde se contemplou o Museu da Saúde, referindo-se a ele o artigo $3^{\circ}$ :

(1) O Museu da Saúde cataloga, preserva e expõe espólios no âmbito da saúde e organiza exposições temporárias ou permanentes sobre temas da saúde.

(2) A coordenação do Museu da Saúde compete a um coordenador, designado por deliberação do conselho directivo, não implicando a criação de cargo dirigente (Portugal, 27 jul. 2007, p.4804).

Com a missão específica de identificar, recolher, preservar, restaurar, catalogar, expor e divulgar o património museológico, bibliográfico e arquivístico de todas as áreas referentes à saúde, a constituição do Museu da Saúde procura, assim, preencher uma lacuna na área da preservação desse tipo de património: a falta de uma política integrada de preservação do património dos serviços que prestam cuidados de saúde e dos que fazem investigação e se dedicam ao ensino em saúde.

Mais recentemente, a portaria 162/2012, de 22 de maio, que aprovou os novos estatutos do Insa, IP, definiu que o Museu da Saúde visa preservar a memória dos serviços de saúde, competindo-lhe:

(1) Proceder ao registo, inventariação e classificação do acervo que lhe está afeto, mantendo atualizados todos os registos documentais referentes às novas incorporações do espólio museológico;

(2) Conservar preventivamente o acervo museológico que lhe está afeto e zelar pela sua segurança, bem como propor ações ou medidas de restauro;

(3) Expor o acervo museológico que lhe está afeto, no âmbito do programa museológico superiormente definido;

(4) Divulgar o acervo museológico e promover a divulgação das suas atividades;

(5) Propor superiormente ações de incorporação de novos testemunhos patrimoniais que contribuam para o enriquecimento do acervo museológico (Portugal, 22 maio 2012, p.2683).

No contexto atual, o Museu da Saúde torna-se de vital importância para a preservação dos bens patrimoniais, especialmente no contexto de reestruturação de serviços (hospitais), constituindo a única instituição dependente do Ministério da Saúde com competências patrimoniais e com a missão de estudar e divulgar a história da saúde em Portugal.

Nesse sentido, o Museu da Saúde em Portugal tem desenvolvido diversas ações de divulgação com o objetivo de sensibilizar técnicos, funcionários e profissionais da saúde para a importância de reunir esses bens e solicitar a presença de técnicos do museu para a avaliação dos mesmos, incorporando-os, quando pertinente, ao seu acervo.

Pese embora a pertinência da incorporação de determinados bens, outros há que a sua manutenção nos espaços de origem lhes confere um maior valor patrimonial pela 
contextualização que lhes é conferida, e, nesse sentido, o Museu da Saúde tem por base conceptual a criação/inclusão de núcleos museológicos ligados à área da saúde, aos quais presta apoio técnico. Ainda dentro desse conceito, o museu tem estabelecido princípios e bases de colaboração com outras entidades, nacionais e internacionais, com o objetivo de criar sinergias visando à conservação, ao estudo e à inventariação do património histórico da saúde, bem como ao desenvolvimento de uma rede virtual museológica por meio da promoção e divulgação das suas exposições temporárias no seu portal in web. ${ }^{5}$

\section{Coleções}

A constituição do acervo do Museu da Saúde português esteve, como vimos, muito relacionada com a recolha de bens por profissionais das instituições a que pertenciam esses objetos ou com transferências de serviços desativados, verificando-se grande diversidade de tipologias de bens, que vai das artes plásticas a objetos e utensílios médicos ou a equipamentos de laboratório.

O desafio do museu consistiu na organização desses objetos e, mediante estudo e classificação, constituir coleções e encontrar um fio condutor que permitisse estabelecer um discurso museológico. Para isso, tornaram-se fundamentais o inventário e a documentação dos objetos e a sua organização em coleções temáticas. Até ao momento, o Museu da Saúde destaca cinco coleções principais, as quais continuam em processo de pesquisa e inventariação:

\section{Tuberculose}

Preserva a memória histórica da luta contra a tuberculose em Portugal, entre os finais do século XIX e as três primeiras décadas do século XX, promovendo e assegurando o enquadramento para as peças históricas de cariz museológico. Trata-se de uma coleção que inclui arte sacra (pintura e escultura), fotografia, aparelhos de tratamento médico (Figura 1) e objetos de uso quotidiano provenientes da Assistência Nacional aos Tuberculosos (ANT). ${ }^{6}$

\section{Urologia}

Doada ao Museu da Saúde pelo Centro de Saúde de Alvalade (Lisboa), integra objetos utilizados nos múltiplos exames complementares de diagnóstico e procedimentos urológicos (Figura 2) realizados na Unidade de Urologia daquele centro, o qual funcionou nas décadas de 1970 a 2010, sendo criada durante a vigência dos Serviços Médico-Sociais e que prestava assistência nessa especialidade a doentes de todo o país.

\section{Psicologia}

Integra diversos objetos utilizados no âmbito da prática clínica (Figura 3) pelo professor Camilo Cardoso (1929-2002), fundador do Departamento de Psicologia Médica da Faculdade de Ciências Médicas da Universidade Nova de Lisboa. Foi doada pela Associação de Antigos Alunos da Faculdade de Ciências Médicas da Universidade Nova de Lisboa. 


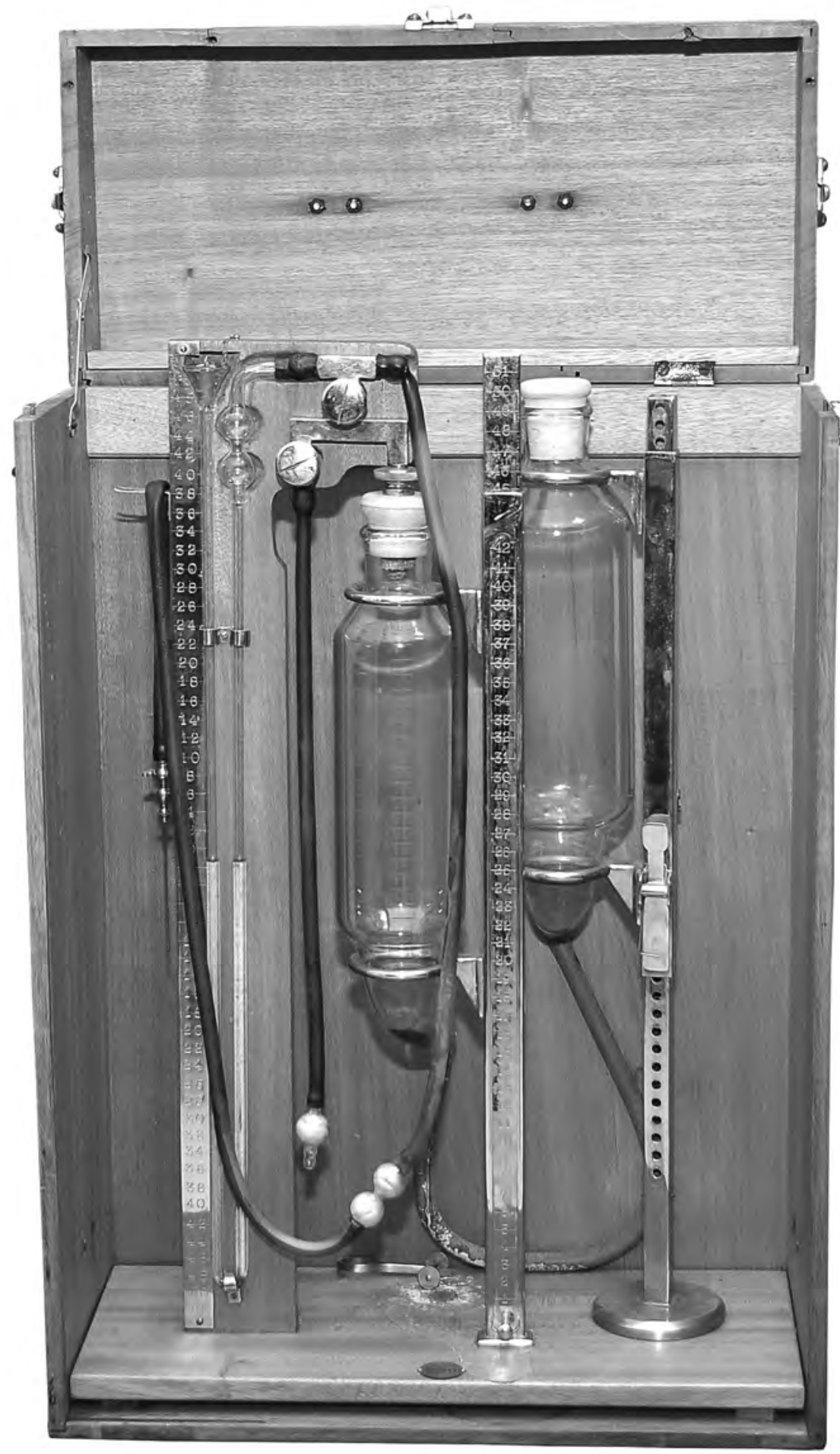

Figura 1: Aparelho de colapsoterapia (Fonte: Coleção Tuberculose, MS.EQP.00035/Arquivo Fotográfico do Museu da Saúde)

Figura 2: Sonda (Fonte: Coleção Urologia, MS.EQP.01033/Arquivo Fotográfico do Museu da Saúde) 


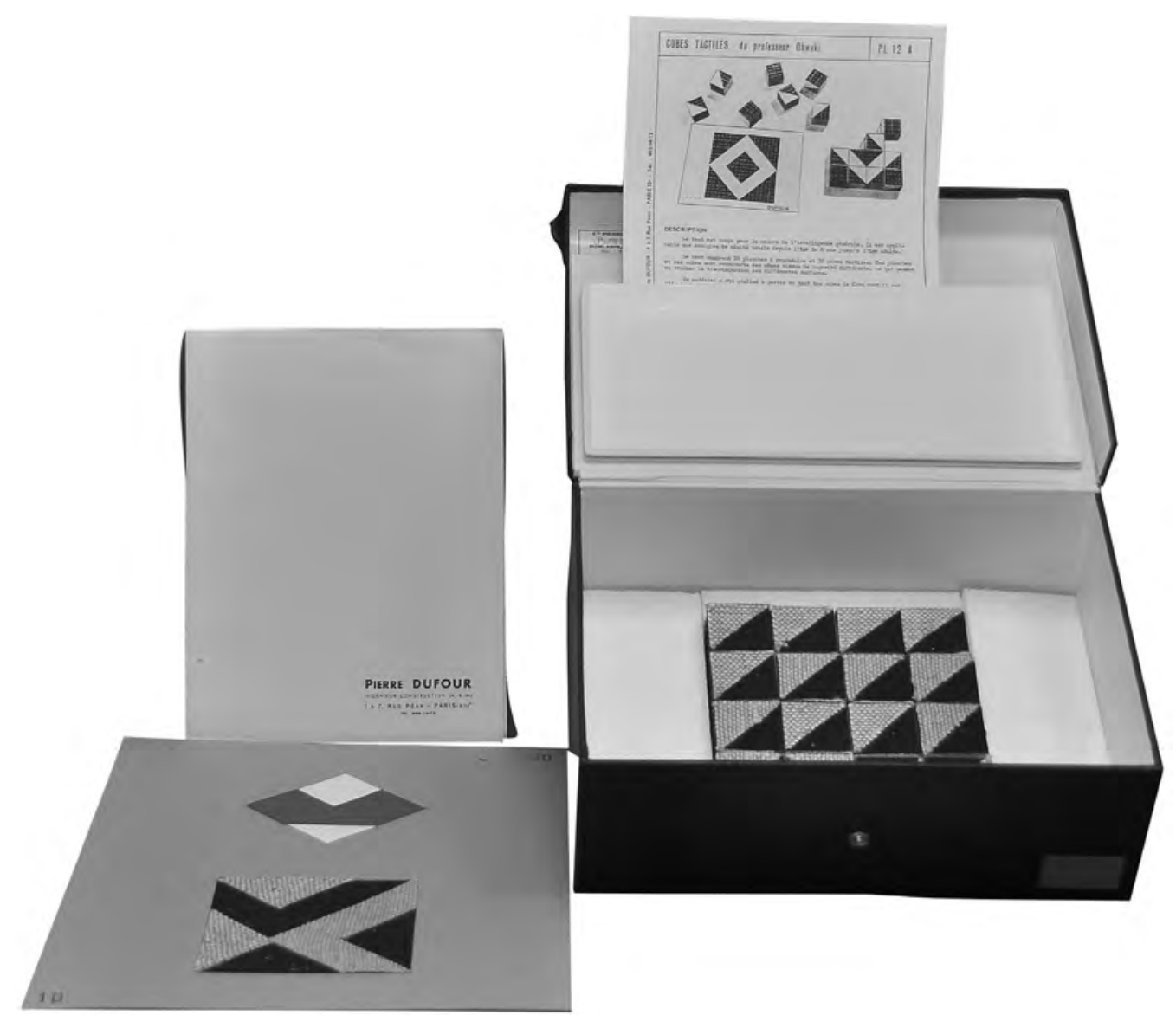

Figura 3: Ergógrafo (Fonte: Coleção Psicologia, MS.EQP.00293/Arquivo Fotográfico do Museu da Saúde)

\section{Medicamento}

Nessa coleção são apresentados exemplares de medicamentos, representando-se aqui o desenvolvimento da química farmacêutica, que permitiu que o "medicamento" fosse produzido em escala industrial e respondesse às necessidades de uma sociedade demograficamente crescente e cada vez mais fármaco-dependente. Integra, ainda, essa coleção aparelhos (Figura 4) e objetos de propaganda médica, permitindo conhecer o seu desenvolvimento e suas transformações estéticas e conceptuais nessa área.

\section{Malária}

Maioritariamente exposta no núcleo museológico de Águas de Moura (Setúbal), a mostra sobre a malária integra diferentes tipologias de objetos (Figura 5), apresentando o papel do Instituto de Malariologia de Águas de Moura, organismo criado em 1938, cuja ação foi crucial no processo de erradicação da malária em Portugal. Como resultado dessa doença e da luta desenvolvida pelo Serviço de Higiene Rural e Luta Antissezonática, foram elaborados diversos documentos e herdado numeroso material de laboratório utilizado na campanha contra a malária em Portugal. 


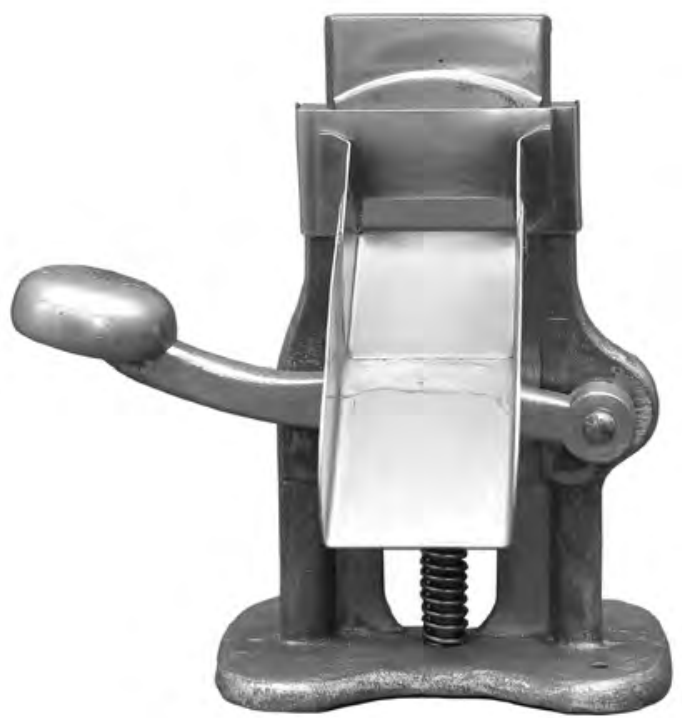

Figura 4: Máquina de fechar bisnagas (Fonte: Coleção Medicamento, MS.EQP.00324/Arquivo Fotográfico do Museu da Saúde)

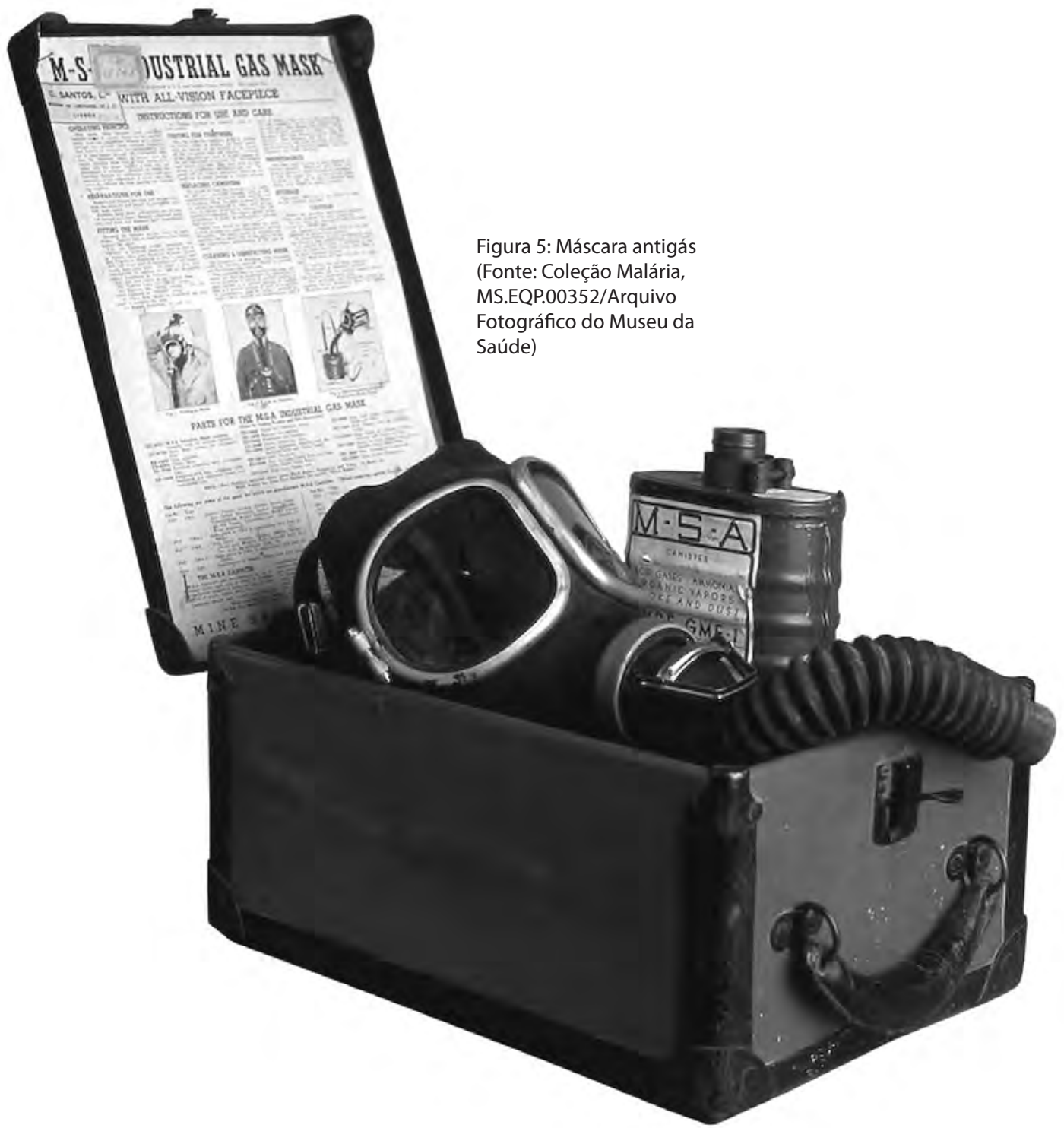


O trabalho de inventariação e estudo do acervo tem permitido a organização de objectos relacionados com outras áreas da saúde e com personalidades relevantes da sociedade portuguesa, sendo, no entanto, as coleções atrás descritas aquelas que o Museu da Saúde estudou mais aprofundadamente até ao momento.

\section{Espaços}

A localização do Museu da Saúde num edifício que serve a outros fins que não museológicos constitui um desafio e coloca algumas questões para a gestão de coleções e realização de outras atividades inerentes à conservação e estudo de património cultural.

De modo a ultrapassar os constrangimentos intrínsecos, o museu tem organizado os espaços que lhe estão afetos em três áreas principais: sala de inventário, reservas e sala de documentação.

A Sala de Inventário destina-se a realizar as tarefas de limpeza e marcação dos objetos, bem como o seu registo numa folha de recolha onde se anotam os dados intrínsecos (medidas, estados de conservação, marcas e inscrições etc.). É, ainda, nesse espaço que se procede o registo fotográfico de cada objeto, captando-se os vários planos e pormenores considerados relevantes para o inventário.

Posteriormente, as peças são colocadas nas salas de reserva, espaços dos antigos biotérios do Insa, IP e que, atualmente, cumprem uma nova função. A sua divisão em salas de média dimensão permite a organização dos objetos por coleção e/ou tipologia, garantindo a sua preservação.

Ainda na zona de reserva, e procurando ultrapassar a ausência de um espaço de exposição permanente, foi organizada uma Sala de Reserva Visitável, conceito que pretende cruzar um espaço de acondicionamento de peças e um espaço de disponibilização de parte do acervo ao público, permitindo o usufruto estético e a realização de atividades lúdico-educativas.

Os objetos foram selecionados pela sua representatividade nas coleções do Museu da Saúde, e o seu estudo e o seu inventário possibilitaram a concetualização da Sala de Reserva Visitável pela intersecção de dois princípios metodológicos: a apresentação temática e a apresentação por coleções.

Foram criados sete núcleos expositivos complementares, colocando-se as peças em móveisvitrine e duas mesas, mobiliário pertencente à ANT e, por isso, com valor histórico.

O primeiro núcleo, dedicado ao Instituto Nacional de Saúde Doutor Ricardo Jorge, apresenta objetos e documentos que remetem para os departamentos e diferentes valências do instituto, ligando-se diretamente com o segundo, dedicado ao doutor Ricardo Jorge, patrono do Insa, IP. Neste, encontram-se peças escultóricas, fotografias, objetos de uso profissional e documentação de sua autoria. Um terceiro núcleo apresenta parte da coleção da Malária, a qual se encontra em exposição permanente num edifício situado na vila de Águas de Moura (concelho de Palmela) e que alberga o Centro de Estudos de Vectores e Doenças Infecciosas, departamento do Insa, IP.

O quarto núcleo apresenta objetos de diagnóstico médico, com especial destaque para o conjunto de esfigmomanómetros de diferentes épocas, os quais permitem uma visualização da evolução técnica desses aparelhos destinados a medir a pressão arterial. 
Os núcleos seguintes são dedicados a quatro das coleções do Museu da Saúde - Medicamento, Tuberculose, Psicologia e Urologia - tendo-se selecionado peças que sejam representativas das várias temáticas e tipologias e que permitam apresentar ao visitante as várias problemáticas relacionadas com cada uma das coleções.

Por fim, no espaço destinado à documentação, desenvolve-se todo o trabalho de pesquisa, registo do inventário em base de dados museológica ${ }^{7}$ e gestão da atividade do Museu.

\section{Inventário e documentação do acervo}

A organização e o inventário do acervo do Museu da Saúde desenvolveram-se, de forma sistemática, a partir de 2011. Tendo em conta a diversidade de tipologias de bens e a pouca informação sobre a proveniência dos objetos e sobre o seu percurso anterior à entrada no museu, foi necessário encontrar uma organização temática, formando-se coleções.

Depois de organizadas as principais coleções, foi estabelecido um plano de inventário, iniciando-se pelo conjunto de objetos ligados a tuberculose, depois malária, psicologia, urologia e, mais recentemente, medicamento. ${ }^{8}$

Utilizando uma metodologia semelhante, o processo de inventário das coleções consubstancia-se nas seguintes fases:

(a) Marcação do objeto com o número de inventário.

(b) Registo fotográfico dos vários planos e pormenores da peça.

(c) Preenchimento da Folha de Recolha com as informações intrínsecas do objeto (designação, descrição sumária, dimensões, materiais, estado de conservação, localização e observações).

Após o processo de inventário, inicia-se a documentação museológica, aqui entendida não apenas como recolha de dados sobre o objeto, pese embora a importância dessa informação, mas objetivando a reflexão sobre o acervo, a produção de conhecimento a partir dele e a construção de um elemento de integração do património na comunidade (Oliveira, 2007).

Assim, entende-se o objeto musealizado como um testemunho e como um documento (Maroevic, 1994), isto é, como a materialidade de uma cultura e de um saber científicos, relacionado com um significado e uma mensagem, e que, quando musealizado, desempenha uma função representativa no contexto de uma narrativa, agregando novos significados (Souza, 2011).

Salientando a função documental dos objetos musealizados, são recolhidos elementos que servem de ponto de partida para a investigação sobre cada peça, tendo-se construído uma matriz de dados $^{9}$ para a orientação da pesquisa (Figura 6).

Seguindo uma metodologia próxima da proposta de Peter van Mensch (1990), pretende-se desenvolver uma documentação em três níveis de dados:

(a) Propriedades físicas e estruturais, incluindo o material, a construção e a forma do objeto (identidade estrutural).

(b) Propriedades funcionais, relacionadas com o uso, utilidade e importância do objeto no que diz respeito ao seu significado e valor (identidade funcional). 
(c) Relações com o contexto, que reporta para o ambiente físico e conceptual em que foi criado/utilizado (identidade contextual/significado).

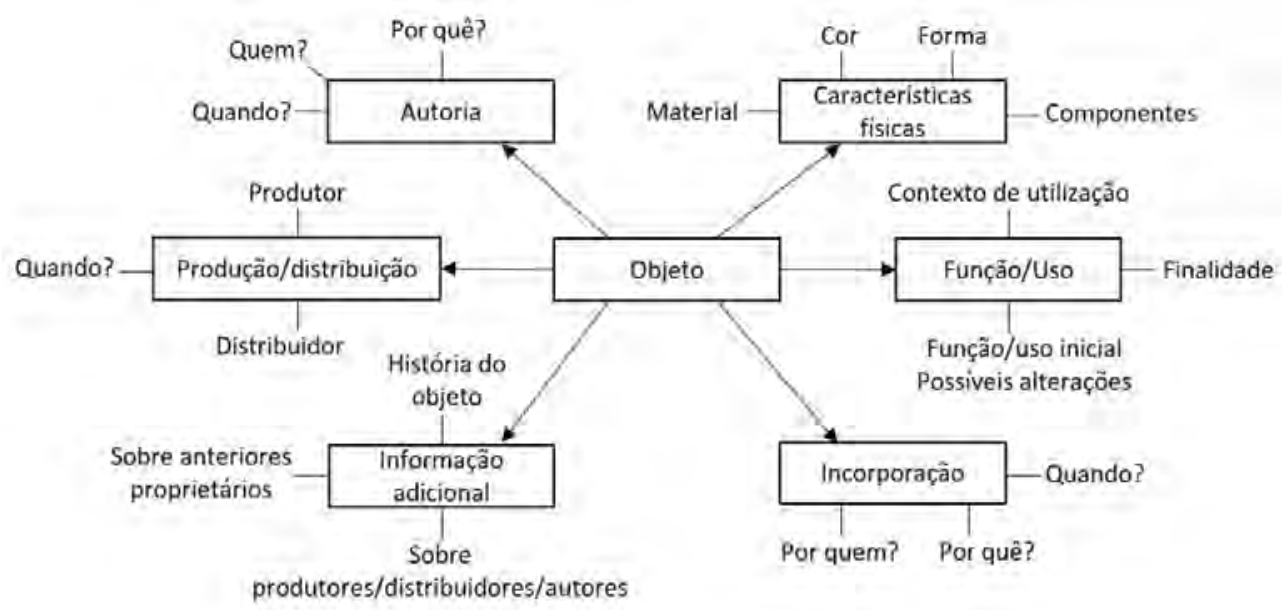

Figura 6: Matriz de dados do Museu da Saúde (Fonte: Oliveira, 2007)

Assim, a pesquisa é direcionada para autorias/produções, funções e usos, proveniência e modo de incorporação, historial do objeto, notas biográficas e outras informações consideradas relevantes.

Cada objeto é, posteriormente, registado no software In Arte Premium, uma base de dados relacional com tabelas auxiliares construídas para responderem às características do acervo e necessidades do museu no que concerne à gestão das coleções. O registo é feito por meio da por meio (preenchimento dos vários campos de texto) e da imagem (fotografias da peça), por meio de campos previamente definidos, o que permite a pesquisa relacional e toda a gestão da coleção, das imagens, das entidades (autores, produtores, técnicos do museu etc.) e dos eventos (exposições, empréstimos, iniciativas educativas etc.).

No processo de inventário e documentação, a normalização de procedimentos é considerada fundamental pelo Museu da Saúde para a gestão da informação sobre o acervo, pretendendo-se desenvolver as boas práticas museológicas com a definição de três tipos de normas, segundo Alexandre Matos (2010): normas de estrutura de dados, que nesse caso se prende com a definição das tabelas auxiliares do In Arte; normas de procedimentos; normas relativas aos conteúdos e linguagem utilizada.

Nesse sentido, foi elaborado um Manual de Procedimentos, em estreita colaboração com o Instituto de Higiene e Medicina Tropical (IHMT), em Lisboa, um dos parceiros do Museu da Saúde. Esse manual visa garantir a uniformização do exercício de inventariação na base de dados In Arte, no sentido em que se descrevem os procedimentos a ter em conta para o preenchimento dos diferentes campos que constituem a ficha de registo, proporcionado a cada inventariante o acesso a um conjunto de instruções e exemplos práticos de modo a facilitar o seu trabalho de documentação.

Esse instrumento auxiliar de trabalho é o primeiro dedicado à área da saúde e será objeto de reflexão e aperfeiçoamento no decorrer do processo museológico e do estudo de novas coleções, pretendendo constituir-se como um documento-base para essa área patrimonial. 


\section{Atividades educativas e de divulgação}

A aposta na divulgação do conhecimento científico resulta de uma nova postura em relação à ciência. Se, inicialmente, era privilégio de uma elite, hoje se pretende massificar o conhecimento científico tornando-o mais acessível à sociedade. Como refere Daniel Souza (2011, p.257), "são empregadas técnicas e métodos de recodificação da informação científica e tecnológica, visando alcançar uma linguagem amplamente compreensível mediante a utilização de meios variados de comunicação".

Os museus de C\&T têm desempenhado um importante papel na divulgação da informação científica, contribuindo, por meio das suas coleções, para a construção da memória e do património científico-cultural. Podemos afirmar que os museus têm um papel mediador entre a produção da ciência e a sociedade. No entanto, não são meros intermediários, na medida em que, na qualidade de instituições de memória que recolhem, preservam, pesquisam, organizam e expõem, integram esse património numa contextualização histórica e, assim, produzem e processam informação, gerando novo conhecimento (Loureiro, Loureiro, 2007).

O Museu da Saúde, como instituição que preserva bens de C\&T, direciona o seu esforço para a promoção da difusão da cultura científica, na área das ciências da saúde e do medicamento, e na conservação do património histórico da saúde. Para isso, tem utilizado meios físicos e virtuais, dirigidos a diferentes públicos.

No que concerne a meios físicos, o Museu da Saúde tem desenvolvido visitas guiadas às exposições temporárias que oferece e à Sala de Reserva Visitável, dirigidas especialmente a grupos escolares e a investigadores na área da saúde. Assim, e tendo em conta as necessidades e conhecimentos de cada grupo, o museu prepara as visitas de modo a responder aos objetivos estabelecidos pelos professores ou investigadores, promovendo percursos diferentes e procurando fornecer documentos de apoio para difusão de conceitos, saberes e práticas ligados à saúde em Portugal.

Para além do público acima mencionado, o Museu da Saúde tem procurado promover uma aproximação com os funcionários do Insa mediante a atividade "15 minutos com o Museu da Saúde", realizada durante o período de almoço. Com essa iniciativa, realizada periodicamente quer às exposições temporárias, quer à Sala de Reserva Visitável, pretende-se promover o usufruto estético e histórico de peças do acervo, bem como explorar temáticas e conceitos por meio dos objetos e da documentação.

No que se refere à Sala de Reserva Visitável, o espaço foi pensado, ainda, para promover um contacto com os técnicos do museu, estabelecendo-se um diálogo com o visitante para apresentação dos objetos, mas também promovendo a sensibilização para a necessidade de preservação dos objetos e para as restantes atividades museológicas de marcação de peças, organização em reserva, estudo e documentação, que se constituem como ações basilares de um espaço de cariz museológico, muitas vezes desconhecidas do público.

Mais recentemente, o museu tem sido convidado para apresentar suas exposições noutros espaços (com especial incidência em instituições estatais da área da saúde), permitindo sua itinerância e divulgação a novos públicos, convites que revelam a projeção que o museu tem conseguido por intermédio das suas atividades para o exterior. 
Concomitantemente, o museu tem apostado no espaço virtual para a divulgação das coleções e exposições, utilizando dois sítios da internet: a página do Insa, IP e a plataforma in web.

Na página da internet do Instituto, foi criado um espaço para o Museu da Saúde, com ligações para conteúdos relacionados com as exposições que vão decorrendo, para as atividades periódicas de divulgação de objetos (Peça do mês) ${ }^{10}$ e para a plataforma in web (Figura 7).

Nessa plataforma é divulgada parte dos campos de informação dos registos previamente inseridos no programa In Arte Premium, não apenas do acervo do Museu da Saúde como de todos os seus parceiros, centralizando a informação, o que constitui uma mais-valia significativa para o público, com especial destaque para os investigadores.

$\mathrm{O}$ in web permite efetuar diferentes tipos de pesquisas: por entidade, em que se agrupam todos os objetos da instituição selecionada; pesquisa geral, que permite pesquisar por palavra; pesquisa específica por número de inventário ou designação do objeto; pesquisa por categoria, em que é possível selecionar uma das categorias e obter uma listagem de objetos, independentemente da entidade a que pertencem; e pesquisa por coleção, em que existe, igualmente, uma listagem de coleções para selecionar.

Nessa plataforma há, ainda, a Peça do Trimestre, iniciativa partilhada por todos os parceiros do Museu da Saúde, segundo a qual, trimestralmente, uma das instituições publica o objeto que selecionou.

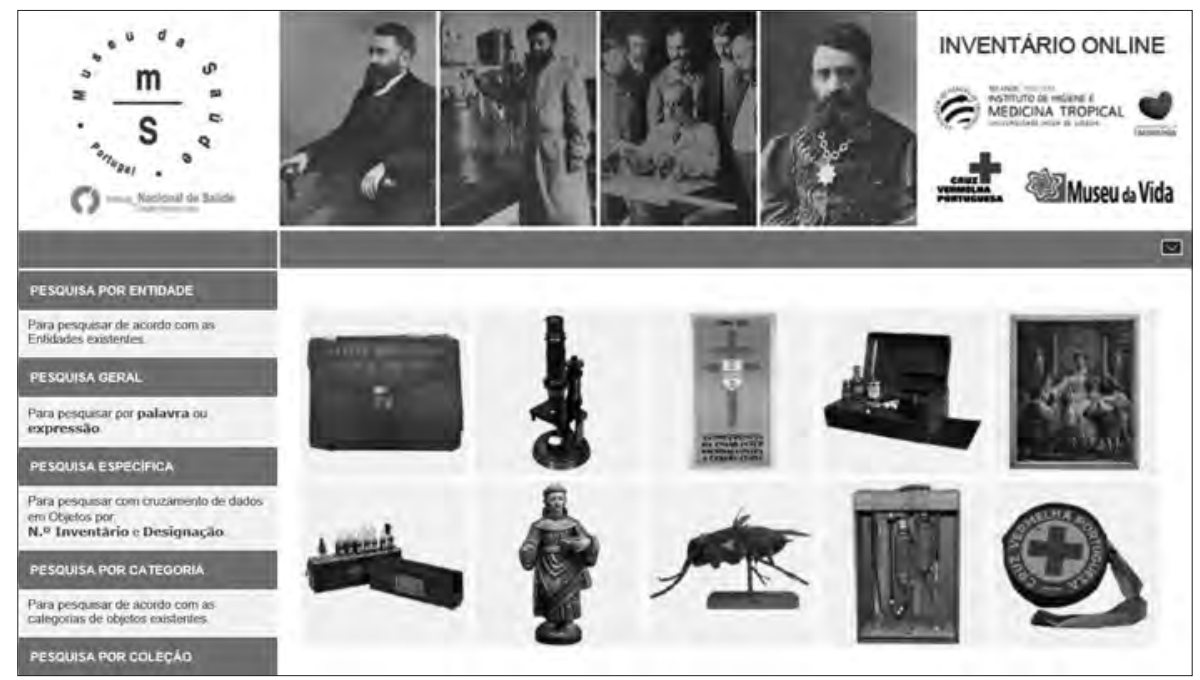

Figura 7: Plataforma in web do Museu da Saúde. Disponível em: http://museudasaude.inwebonline. net/default.aspx

Esse inventário on-line está em permanente atualização, sendo alimentado pelas bases de dados do Museu da Saúde, da Cruz Vermelha Portuguesa, do IHMT e do Museu da Vida (Brasil), possibilitando a divulgação dessa atividade museológica de várias instituições ao público em geral, numa única plataforma.

Por meio dos recursos virtuais, o Museu da Saúde tem procurado tornar mais acessível a informação sobre os objetos, bem como disponibilizar textos expositivos e referências 
bibliográficas. Nesse sentido, tem-se verificado que o espaço virtual veio auxiliar o museu na sua comunicação com o público, dado que muitos dos seus visitantes contactam os serviços depois de, numa primeira fase, terem tomado conhecimento das atividades e conteúdos por intermédio da internet.

A disponibilização do acervo on-line, quer do Museu da Saúde, quer dos seus parceiros, tem constituído uma mais-valia para o público escolar e para os investigadores, que aqui encontram uma base de dados centralizada e normalizada de informação.

\section{Considerações finais}

A atividade museológica do Museu da Saúde, em Lisboa (Portugal), tem permitido a organização do acervo, o seu inventário e a documentação, bem como a divulgação ao público.

Pensando numa perspetiva de futuro, o museu considera que existem duas vertentes que deverão ser objeto de análise e constituir-se como objetivos de médio prazo - uma liga-se à documentação museológica, e outra, à criação de nucelos museológicos.

No que se refere à primeira, o grande desafio do Museu da Saúde será a criação de um thesauri para objetos dessa área específica de património, bem como a afinação de metodologias de inventário, de conceitos e de classificação, tornando-se referência para a documentação museológica desse tipo de acervos.

Essa vertente deverá ser acompanhada de outra, que se prende com a preservação dos objetos dispersos pelo país, em diferentes instituições e vários estados de acondicionamento/ segurança, realidade que urge conhecer, inventariar, estudar e divulgar, pois, conhecendo o acervo no nível nacional se poderá preservar o património da saúde em Portugal.

Para a concretização dessas duas vertentes e futuro desse projeto, a criação de parcerias com outras entidades museológicas, com instituições da saúde e de ensino superior, em Portugal e no estrangeiro, será de grande pertinência.

No que concerne à difusão da cultura científica na área da saúde, missão desse museu, apresenta-se como principal desafio o aproveitamento da virtualidade para alargar e multiplicar os públicos, mas também as experiências sensoriais.

Atualmente, o Museu da Saúde disponibiliza as suas coleções numa plataforma on-line, o in web, permitindo a pesquisa dos objetos por parte dos utilizadores. Contudo, outras experiências interativas devem ser promovidas. Pelo seu duplo conceito de espaço físico e virtual, o museu poderá encontrar na internet uma ferramenta fundamental para se comunicar com o público, nomeadamente pela criação de um "Museu da Saúde Virtual", o qual iria permitir disponibilizar as coleções de forma mais permanente, complementando o espaço físico que venha a ter para o efeito.

\section{NOTAS}

${ }^{1}$ O Museu da Saúde está localizado no Instituto Nacional de Saúde Doutor Ricardo Jorge (Insa, IP), em Lisboa. Atualmente, tem um núcleo em Águas de Moura (Palmela, Setúbal) dedicado à coleção da malária.

${ }^{2}$ O Museu da Saúde tem a sua página da internet localizada no sítio do Insa, IP: http://www.insa.pt/sites/ INSA/Portugues/MuseuSaude/Paginas/MuseuSaudeNovo.aspx. Tem, ainda, uma plataforma em que divulga o inventário do seu acervo e das instituições parceiras: http://museudasaude.inwebonline.net/ (Insa, 2012). 


\begin{abstract}
${ }^{3}$ No portal do Museu da Saúde é possível pesquisar as coleções dessa instituição, bem como da Cruz Vermelha Portuguesa, do IHMT, Portugal, e do Museu da Vida da Fundação Oswaldo Cruz (Fiocruz), Brasil.

${ }^{4} \mathrm{O}$ Insa, IP foi fundado em 1899, então como Instituto Central de Higiene. Anos mais tarde, pelo decreto 16.861, de 11 de maio de 1929, foi dado àquele instituto o nome do Doutor Ricardo Jorge, nomenclatura que viria a manter até 1945, ano em que passou a designar-se Instituto Superior de Higiene. Em 1971, o Insa veio, finalmente, a receber a designação atual. Ao longo de todo esse período, no qual se vem materializando sua já longa história, o Insa tem vindo a acompanhar e intervir ativamente no incessante desenvolvimento científico e tecnológico que se vem registando no domínio da saúde.

${ }^{5}$ Portal disponível em: http://museudasaude.inwebonline.net/.

${ }^{6}$ Instituição fundada pela rainha dona Amélia, em 1899, com o objetivo de criar sanatórios por todo o país e outras estruturas para tratamento dos doentes e prevenção da doença.

${ }^{7}$ O Museu da Saúde desenvolve o seu inventário na base de dados In Arte Premium, a qual foi adaptada às características e necessidades do seu acervo.

${ }^{8}$ Salienta-se que o inventário dessas coleções não se considera terminado, dado que novos objetos vão sendo incorporados a elas.

${ }^{9}$ A matriz de dados foi criada com o objetivo de orientar a pesquisa para a documentação das coleções, e pretende-se que seja aperfeiçoada com a continuidade da investigação por forma a incluir novas variáveis.

${ }^{10}$ Essa atividade teve início em fevereiro de 2012 e tem destacado, mensalmente, um objeto do acervo, com o objetivo de evidenciar temas e tipologias de objetos com elevado valor histórico e científico.
\end{abstract}

\title{
REFERÊNCIAS
}

INSA.

Instituto Nacional de Saúde Doutor Ricardo Jorge - Museu da Saúde; Instituto de Higiene e Medicina Tropical. Manual do inventário do património museológico da saúde: guia prático. Lisboa. Disponível em: http://www.insa.pt/ sites/INSA/Portugues/MuseuSaude/Documents/ MS_ManualProcedimentos.pdf. Acesso em: 12 dez. 2013. 2012.

LOUREIRO, José; LOUREIRO, Maria Lucia. Museus e divulgação científica: singularidades da transferência da informação científica em ambiente museológico. Trabalho apresentado no 7. Encontro Nacional de Ensino e Pesquisa da Informação, 2007, Salvador. 2007.

LOURENÇO, Marta C.

A recuperação patrimonial da Associação Protectora da Primeira Infância: um património singular e uma iniciativa notável. Trabalho apresentado à Associação Protectora da Primeira Infância, Lisboa, 2012. (No prelo).

MAROEVIC, Ivo.

The museum object as a document. In: Schärer, Martin R. (Ed.). Symposium Object-Document? Beijing: International Council of Museums; International Committee for Museology. p.113120. Disponível em: http://network.icom. museum/fileadmin/user_upload/minisites/ icofom/pdf/ISS\%2023\%20(1994).pdf. Acesso em: 12 dez. 2013. 1994.

MATOS, Alexandre.

Normalização de procedimentos nas colecções museológicas. In: Seminário de Investigação em Museologia dos Países de Língua Portuguesa e Espanhola, 1., 2010, Porto. Actas... Porto: Faculdade de Letras da Universidade do Porto. v.3, p.27-35. 2010.

OLIVEIRA, Inês Cavadas de. Intervenção museológica no património escolar: o caso do Projecto de Inventário do Património Museológico da Educação. Dissertação (Mestrado em Museologia) - Departamento de Arquitetura, Urbanismo, Geografia e Artes Plásticas, Universidade Lusófona de Humanidades e Tecnologias, Lisboa. 2007.

\section{PORTUGAL.}

Ministério da Saúde. Portaria 162/2012, de 22 de maio de 2012. O decreto-lei 27/2012, de 8 de fevereiro, definiu a missão e as atribuições do Instituto Nacional de Saúde Doutor Ricardo Jorge, I.P. (Insa, I.P.). Importa agora, no desenvolvimento daquele diploma, determinar a sua organização interna através da aprovação dos respetivos estatutos. Diário da República, $1^{\text {a }}$ série, n.99, p.2679-2683. Disponível em: https://dre.pt/application/dir/ pdf1sdip/2012/05/09900/0267902683.pdf. Acesso em: 20 nov. 2015. 22 maio 2012.

\section{PORTUGAL.}

Ministério da Saúde. Portaria 812/2007, de 27 de julho de 2007. O decreto-lei 271/2007, de 26 de julho, definiu a missão e atribuições do Instituto Nacional de Saúde Doutor Ricardo Jorge, I.P. Importa agora, no desenvolvimento deste decreto-lei, determinar a sua organização 
interna através da aprovação dos respectivos estatutos. Diário da República, Lisboa, $1^{\text {a }}$ série, n.144, p.4803-4805. Disponível em: https://dre. pt/application/file/636324. Acesso em: 20 nov. 2015. 27 jul. 2007.

PORTUGAL.

Ministério da Saúde. Decreto-lei 271/2007, de 26 de julho de 2007. Reestruturação da Administração Central do Estado (Prace) e dos objectivos do Programa do Governo no tocante à modernização administrativa e à melhoria da qualidade dos serviços públicos... Diário da República, Lisboa, $1^{\mathrm{a}}$ série, n.143, p.4780-4785.
Disponível em: https://dre.pt/application/ file/636618. Acesso em: 20 nov. 2015. 26 jul. 2007.

SOUZA, Daniel Maurício Viana.

Ciência para todos? A divulgação científica em museus. Ciência da Informação, v.40, n.2, p.256-265. 2011.

VAN MENSCH, Peter.

Methodological museology; or, towards a theory of museum practice. In: Pearce, Susan (Ed.).

Objects of knowledge. Leicester: The Athlone Press. p.141-157. 1990.

\section{$\rightarrow \rightarrow \rightarrow<<<$}




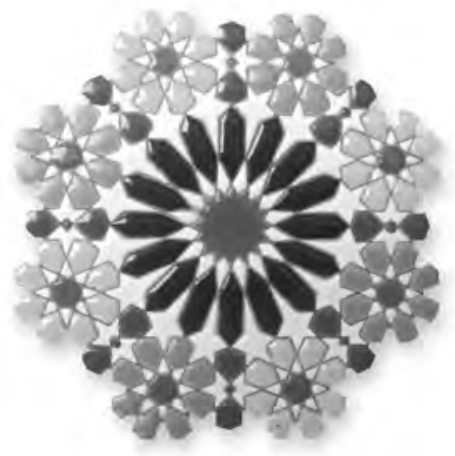

